\title{
DHM in Human-Centered Product Design: A Case-Study on Public Transport Vehicle
}

\author{
Santos $^{2}$, V.; Guimarães ${ }^{1}$, C.P.; Franca ${ }^{1}$, G. A. N.; Cid ${ }^{1}$, G.L.; Paranhos $^{1}$, A. G.; \\ ${ }^{1}$ Instituto Nacional de Tecnologia - INT/ MCT \\ ${ }^{2}$ Pontifícia Universidade Católica do Rio de Janeiro PUC-Rio
}

\begin{abstract}
The goal of this paper is to present the advantages on the use of 3D Digital Human Models (DHM) on the design of public transport vehicles. In this case, the subjects were scanned using the WBX Cyberware 3D Whole Body Scanner, with functional and daily postures according to the use of public transportation and some especial cases, such as a mother with her offspring or a business man with his valise, so the volume of the person would be taken in consideration. A data collection was created to simulate several situations of the daily use of the vehicle.
\end{abstract}

Keywords: ergonomics, occupancy, magnetic levitation train and digital human model

\section{Introduction}

In product design, ergonomics guides the selection of product features and design characteristics that will improve safety, comfort, and performance of users. For transportation vehicle design, for instance, that must be built and used by humans so the design must accommodate a wide range of heights, strengths, ages and postures and so on. One important aspect of human behavior that is relevant to ergonomic analysis is volitional, task-oriented movement. As can be readily seen, there is substantial variation in the way that people move or be in a stand equilibrium posture inside a transportation vehicle, which depends on their physical size, gender, age and other factors. There is also natural, but unexplained, variation in human movement, sometimes influencing by handling things like bags, purses, and so on.

Computer-aided design tools increasingly allow ergonomics considerations to be addressed early in the design of products and industrial processes through computer simulations. In the past, many physical prototypes were built in order for a product or a process to be evaluated. This time-consuming, traditional way tends to be replaced by the process of virtual prototyping and by digital humans representation. The idea of simulating the human motion during the study of human functionality in working environments or using products, aiming at designing for ergonomics (Badler et al., 1999), has been approached by many researchers in recent years. Human capabilities, requirements, and performance are represented in these simulations through the use of digital human models (DHM), software avatars that represent human size, shape, strength, vision, and movement as they interact with virtual geometry and environments (Chaffin (2001). DHM are now widely used in the design of products, particularly aircraft, cars, trucks, and other vehicles. Industrial manufacturers are also increasingly using DHM to simulate workers in computer simulations of new plants or processes. (Porter, Case, Freer, and Bonney, 1993) The representation of realistic human movements in virtual environments is crucial for the reliability of simulation results.

The need for Digital Human Model (DHM) has been demonstrated by the numerous publications and applications. The main useful application of DHM can be summarized as (i) replication of a pattern and simulation (ii) prediction (proactive analysis), (iii) prescription and (iv) visualization. Actual applications have been reported for a wide range of product development, understanding behavior, learning processes, etc. Digital human modeling has been applied in ergonomics design and analyses for a long time. By integrating dynamic simulation and ergonomics evaluation, digital human modeling enables the system or product designer to visualize and 
improve workplace or products design in the digital space.

The project was conducted by UFRJ (Federal University of Rio de Janeiro), INT ( National Institute of Technology Brazil) and Ergon Projetos (an ergonomics design Brazilian company) for defining the interior layout of a modular vehicle that uses magnetic levitation technology for public transport. One of the main layout aspects was to establish the number of people for each vehicle's module. To establish that, one-dimensional and threedimensional anthropometry approaches were used.

\section{Methodology}

Due to this complexity, design conflicts arise in almost any design assignment. The designer has to cope with such conflicts and find an optimal solution within the available design space. (MOES, 2010)

There was an important issue related to the vehicle module final weight that is directly associated to the magnetic levitation of the module and the number of passengers (design constraints). It was indispensable to consider the diversity in terms of passenger demographics, age, loss of mobility and balance, the disabled and people sensitive to acceleration (prone to motion sickness) so it should provide interior layout flexibility. For example, for older people, pregnant women and children, it should have seats, safety system or support to facilitate their balance, individuals with disabilities who use wheelchairs or other mobility aids system must have guaranteed access and ease of movement in the modules. To accommodate obese people, the seats and seat backs must have bigger dimensions and a place must be provided to allocate the bags, backpacks and other accessories that will be transported. (for these issues we took into consideration Brazilian Norms for public transportation such as ABNT NBR Norma 15570:2008, ABNT NBR Norma 15570:2008/Em.1:2009, ABNT NBR Norma 14022:2006 and ABNT NBR Norma 14022:2006/Em.1).

Design Premises: Occupation by people with different proportions, the access (ex. doors): entering and leaving the train considering 1,20 m doors, circulation inside the train (compressed space) and different postures taken in order to facilitate air circulation and less feeling of confinement

The 3D mannequins were generated from the tridimensional anthropometry methodology, using Cyberware 3D scanner, that allowed to scan virtual models of users in different postures and also with different fittings as backpackers, bags, etc. These models are used in the layout and occupancy study. (Figure 1 and 2)

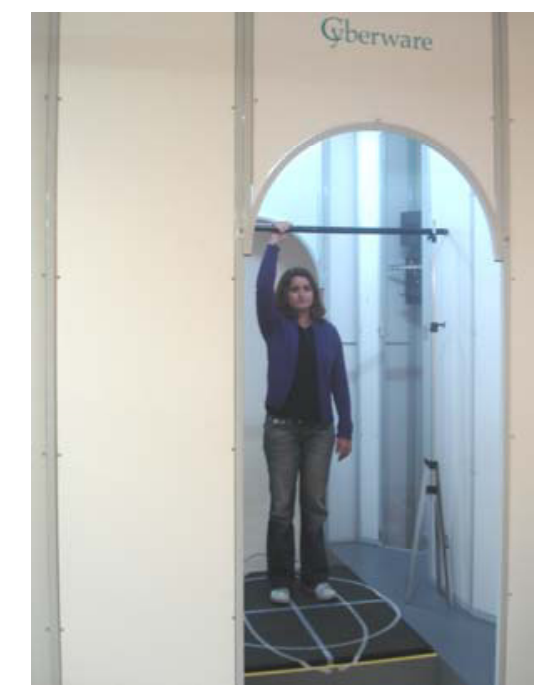

Fig1. Scanning

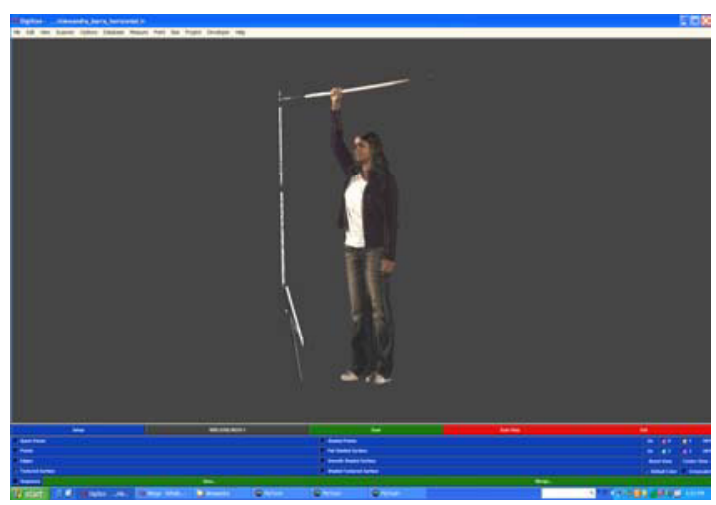

Fig. 2 - Scan generated. with subject holding a bar

Some design alternatives were tested using both 1D and 3D mannequins.

Some examples are display below:

Door and passengers modules layout options, considering ideal ergonomic situation

\section{Layout study using 2D mannequins}

In the layout 1 it was possible to place, in a comfortable way, 4 seated users, 10 semi-seated and 10 
standing, in a total of 24 people, as shown in figure 3.

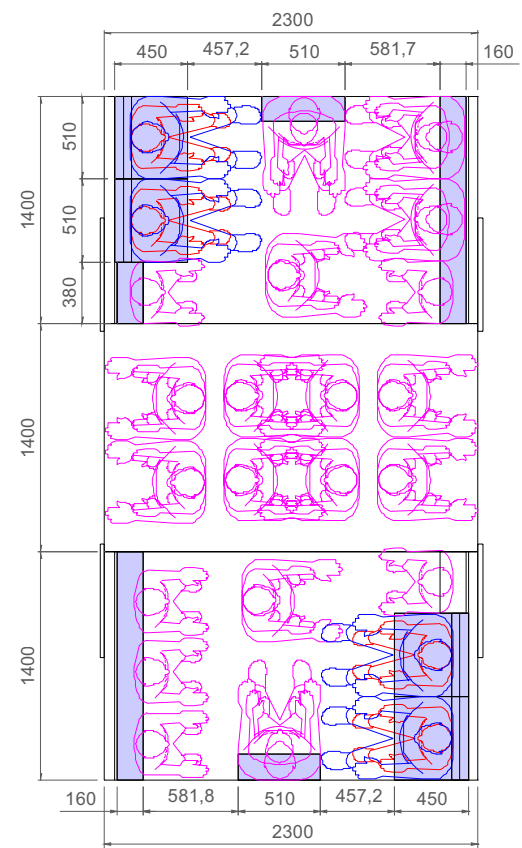

Fig. 3 Alternative 1

\section{- Occupancy study using 3D scanner.}

Taking alternative 1 as a start, a 3D mockup was generated and 3D scans were inserted. It was concluded that it would not be able to support the 24 people the $2 \mathrm{D}$ layout study was showing. It could have 20 users, as shown in the figures $4,5$.

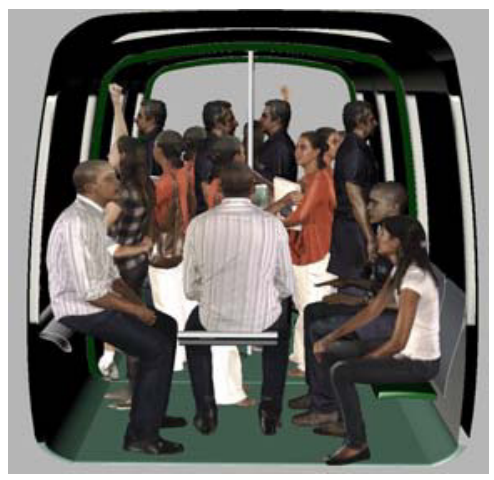

Fig. 4 - Alternative 1: Occupation study using 3D scans (frontal view)

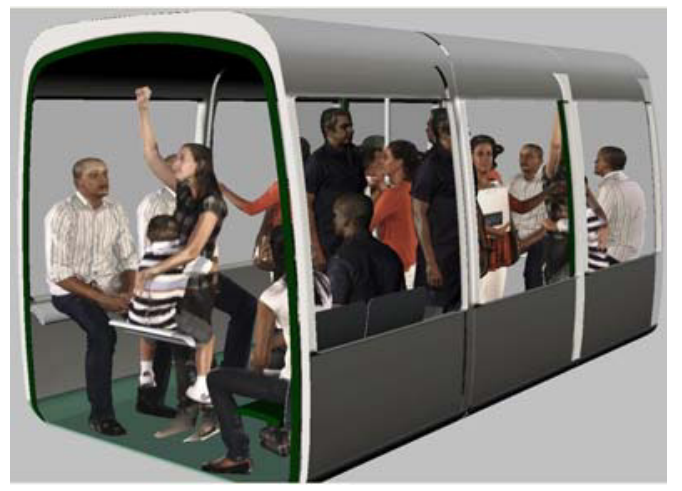

Fig.5 - Alternative 1: Occupation study using 3D scans (lateral view)

\section{- Maximum occupancysStudy}

In order to help the modules size definition, a maximum occupation study were made, considering the same alternatives shown before.

- Smaller people ( 5 feminine percentile, data from ERGOKIT/INT)

- Taller people (95 masculine percentile, data from ERGOKIT/INT)

In relation to weight variable, it was considered as a reference to the 95 masculine percentile, the PEA RESEARCH (ERGOKIT/INT), and the value is $85,9 \mathrm{Kg}$. To the 5 feminine percentile it was considered the SERPRO RESEARCH (ERGOKIT/INT), which value is $43,7 \mathrm{~kg}$.

In the example above, alternative 1 was possible to fit, maximum of 61 women ( 5 feminine percentile), with a total weight of $2.665,7 \mathrm{~kg}$ in the three modules. In other words, it's about $635 \mathrm{~kg}$ per meter. Using 34 men (95 masculine percentile), it had a total weight of $2.920,6 \mathrm{~kg}$ in the three modules. In other words, it's about $695 \mathrm{~kg}$ per meter. (Figure 6, Figure 7) 


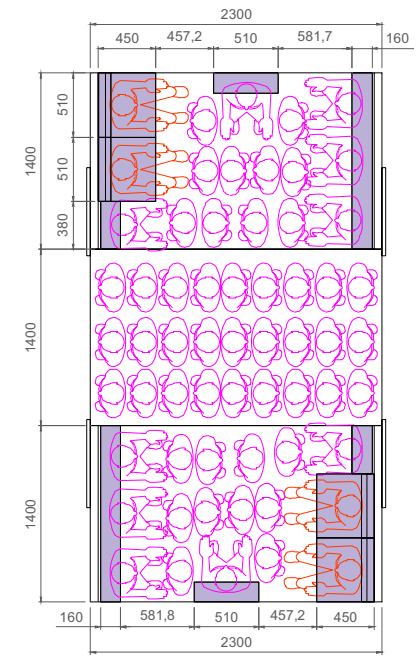

Fig. 6 - Alternative 1 Maximun Occupation (P5)

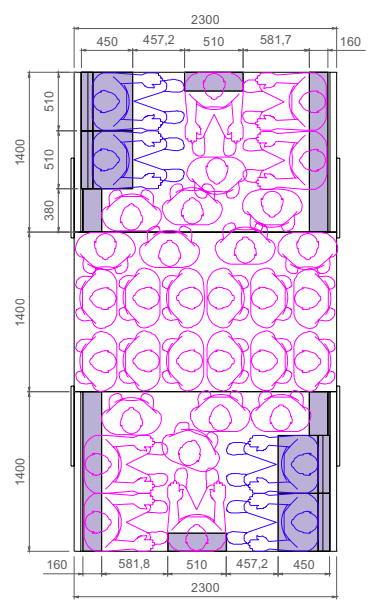

Fig. 7 - Alternative 1 Maximun Occupation (P95)

The weight will never be a constant and may vary between 614 a $718 \mathrm{~kg}$, considering 5 feminine percentile and 95 masculine percentile that were taken as reference. And also should be considered the objects weight that each users carry. When 3D scans are used, it is able to see that the solution proposed by $2 \mathrm{D}$ mannequins could lead to a bigger number of passengers. The same isn't possible with the $3 \mathrm{D}$ mannequins, as they are present in several positions and postures.

\section{Layout Project}

The layout project must have references to the standards and also incorporate the mobility of the user population, as a mean of security, evacuation and circulation questions.

\section{- Study of the internal arrangement}

Having in view the standards revision we suggest the following layout exposed below, that should be discussed and adjusted, even the seats positioning (Figure 8).

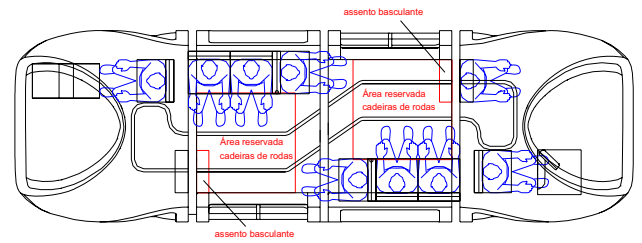

Fig. 8 - Internal Layout.

In this layout it's possible to place comfortably: in the two central modules $=20$ people and in the extremity modules $=2$ people and the operator

In this way we will have a total of 23 people, if we consider the 95 percentile (considering the weight of the male 95 percentile as $85,9 \mathrm{~kg}$ and 43,7 for the female 5 percentile), adding $10 \%$ from accessories (clothing, backpacks, shoes and other).

Considering at the internal arrangement, the users with disabilities, the area reserved for the wheel chair was allocated near the boarding door and place in the longitudinal direction of the vehicles movement.

A $1200 \mathrm{~mm}$ by $1200 \mathrm{~mm}$ free area to allow turn, movement and accommodation for the wheel chair in the reserved area. In the reserved area is foreseen an individual folding seat (Figure 9)

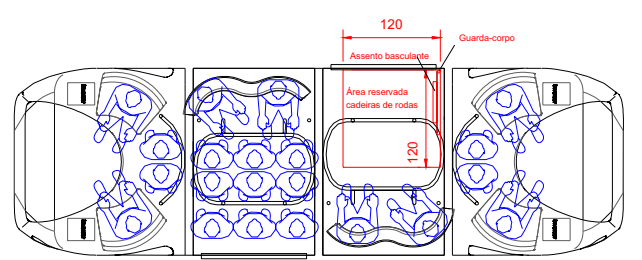

Fig. 9 - Reserved area

- Study of Internal arrangements with pillar, rail and supports in the passenger lounge.

The pillars were positioned to allow the safe movement of the users, especially people with low 
mobility and reduced stature, within the entry and exit of the vehicle. (Figure 10)

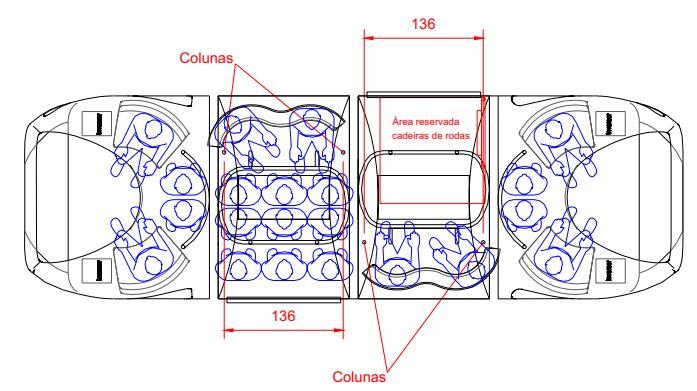

Fig. 10 - Pillars positioning

OBS: NBR 15570:2008 - the columns, rails and supports should be constructed with circular section with external diameter between 30 and $40 \mathrm{~mm}$ enduring a $1500 \mathrm{~N}$ force applied in an equidistant point from the extremities fixation, and in the case of the superior rail, a $400 \mathrm{~N}$ force every $200 \mathrm{~mm}$ in length.

All the points between the entry and exit from the vehicle must tend to the item 7.3.3 from the ABNT NBR 14022:2009 (internal vehicle communication).

There should be pillars with $2000 \mathrm{~mm}$ spacing, positioned alternately to the right and left side of the circulation corridor, guaranteeing the user a support point every $1000 \mathrm{~mm}$, approximately. (Figure 11)

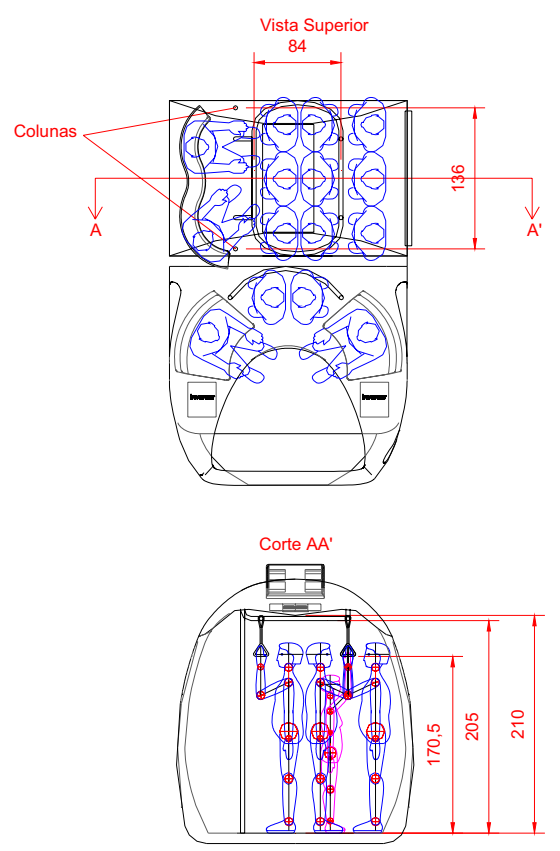

OBS: NBR 15570:2008 - for low floor vehicles, there should be straps movable installed, sliding or attached to the rail, positioned at least near the wheel boxes, in minimal quantity of two units, providing handgrip between 1650 to $1750 \mathrm{~mm}$ from floor level. For situations where the distance from the seat, in relation to the opposite surface or central bench is superior to $400 \mathrm{~mm}$, there should be installed a hand rail.

\section{References}

1. BRATMILlER, B. , GORDON, C.C. , KOUCHI, M. JÜRGENS, W.H. , LEE, Y. Traditional Anthropometry, Working Postures and Movements, edited by Nico Delleman, Christine M. Haslegrave and Don B. Chaffin, 2004. 2. ABNT NBR Norma 15570:2008 - Transporte - Especificação técnicas para fabricação de veículos de características urbanas para transporte coletivo de passageiros 3. ABNT NBR Norma 15570:2008/Em.1:2009 4. ABNT NBR Norma 14022:2006 - Acessibilidade em veículos de características urbanas para o transporte coletivo de passageiros

5 ABNT NBR Norma 14022:2006/Em.1:2009 6. ROBINETTE, M.K., DAANEM, A.M.H. , ZEHNER, F.G., Three-Dimensional Anthropometry, Working Postures and Movements, edited by Nico Delleman, Christine M. Haslegrave $\begin{array}{lll}\text { and Don } & \text { B. Chaffin, } & 2004 .\end{array}$ 7. PASTURA, F.H; GUIMARÃES, C.P., ZAMBERLAN, M.C., SANTOR, V., TEIXEIRA, R.C., OLIVEIRA, J.L., CID, G.L., TAVEIRA, G., MOURÃO, P.T., 3D Laser scanning technology applied to ergonomics projects. WEAR Valencia, 2010.

9. MOES, N.C.C.M. Digital Human Models: An Overview Of Development and Applications in Product and Workplace Design, Proceedings of TMCE 2010 Symposium, April 12-16, 2010 10. CHAFFIN, D. (Ed.) (2001). Digital Human Modeling for Vehicle and Workplace Design. Warrendale,PA: SAE International. Chaffin, D., G. Andersson, and B. Martin

11. BADLER, N., BINDIGANAVALE, R., BOURNE, J., ALLBECK, J.,. SHI, J. AND M. PALMER. "Real time virtual humans", International Conference on Digital Media Futures, Bradford, UK, abril de 1999. 